\title{
Experience and advice from single medical center: how to rescue patients with serious COVID-19 and protect medical staffs without sufficient personal protective equipment
}

\author{
Hua Luo", Sheng Zhang", Yingxin Lin, Bin Huang, Yunliang Tu, Yanyan Li, Cong Zhou, Xinxin Wang \\ MICU, Peking University Shenzhen Hospital, Shenzhen, China \\ \#These authors contributed equally to this work. \\ Correspondence to: Hua Luo, MICU of Peking University Shenzhen Hospital, No 1120, Lian hua Road, Fu tian District, Shenzhen, China. \\ Email: luoxiaoer@hotmail.com. \\ Provenance and Peer Review: This article was a free submission to the journal. The article was sent for external peer review.
}

Submitted Mar 22, 2020. Accepted for publication May 12, 2020.

doi: $10.21037 / \mathrm{cdt}-20-379$

View this article at: http://dx.doi.org/10.21037/cdt-20-379

From the beginning of 2020, the people of China and all over the world have been under the imminent threat of COVID-19. Since the Spring Festival in February, many Chinese ICU specialists have been supporting and directing the rescue of severe patients in Wuhan city. Collectively, they have accumulated large amounts of clinical experience that cannot yet be found in the literature. While the spread of disease in Wuhan has been controlled gradually and the epidemic situation in China has significantly improved, other countries are struggling with the pandemic.

Shenzhen city has not been prominently affected by the epidemic diseases because of good epidemiologic management. The first serious COVID-19 patient with intubation in the Guangdong province, a case of severe ARDS with oxygenation index in 50, was successfully rescued in our ICU during the early outbreak stage in midJanuary. Subsequently, he was transferred to an Infectious Disease Hospital for quarantine and further treatment. No evidence of nosocomial infections of COVID-19 was found among our medical staff, although we did not fully understand the disease at that time.

\section{The following statements about how to rescue patients with serious COVID-19 summarize our experience:}

(I) Do not hesitate to perform intubation as soon as possible;

(II) Large dose of vitamin C (8-10 g/day) for the fulminant myocarditis and sepsis;

(III) $\quad 60-80 \mathrm{mg} /$ day of Methylprednisolone for relieving alveolar consolidation. Early discontinuation during the recovery period would lead to rebound disease and acute pulmonary fibrosis appearance;

(IV) Prone position ventilation beginning with a platform pressure less than 25 in patients with structural pulmonary disease;

(V) Initiating early CRRT to assist the fluid resuscitation and keep the balance between the leakage period and abnormally elevating NT-proBNP;

(VI) Combine antibiotics with sepsis therapy;

(VII) Hemoptysis might imply pulmonary vascular involvement in the early stage due to ACE2 in capillary endothelial affected by virus. In the later stage, pulmonary vascular remodeling and a large amount of mucin exudation from pulmonary vessels into alveoli would aggravate pulmonary fibrosis and pulmonary hypertension. We thought protective treatment of pulmonary vascular endothelium, low molecular weight heparin, fasudil and the treatment reducing hyperbradykinemia might be helpful;

(VIII) ECMO could not solve the problem of fibrosis. The $\mathrm{V}-\mathrm{V}$ model might not be suitable for patients with pulmonary hypertension;

(IX) Active daily alveolar drainage by the fibro bronchoscope;

(X) Large dose of ambroxol, acetylcysteine and ulinastatin might protect the alveoli; 
(XI) Chinese medicine showed potential on symptom improvement.

\section{Over the world, many medical staffs are facing a shortage of masks and other protective gear. Under circumstances without enough personal protective equipment (PPE), we suggest that medical staffs can try to protect themselves as following}

\section{For medical staffs not working in ICU}

(I) If a used face mask is dry and not contaminated by the patient's secretions, placement under an ultraviolet lamp and re-use could be considered. Wet masks could be dried and re-used after adding a layer of water- and oil- proof tissue, such as disposable sterile disinfection towel, on the inner side of the mask. It will be less comfortable but maybe helpful;

(II) Swimming goggles and kitchen oil proof shield can be used as an alternative for eye protection. They can all be soaked in medical alcohol and reused. In the radiology department, transparent radiographs can be used to make face shields;

(III) Be sure to follow a good habit of hand hygiene. Focus on protecting eyes, nose and mouth. Keep in mind that the mask is wore first and taken last. Near half of iatrogenic infections come from the process of removing the mask. Do not touch the contaminated surface of the mask;

(IV) Using regularly chlorine dioxide spray and ultraviolet lamp twice a day to make the environment sterile. Personal can prepare own chlorine dioxide solution with concentration recommend of 1:1,000 to wipe the object surface at home;

(V) Personal items such as glasses, mobile phones, keys and stethoscopes can be wiped with medical alcohol;

(VI) For close interaction and procedures (patients within one meter), such as sputum aspiration, intubation, puncture, caregivers should wear N95 masks, caps, goggles, feet sleeve, protective clothing and double-layer gloves. Otherwise, surgical masks and isolation suits will do just for consultation with patients one meter away. Instruct patients to wear a mask while talking;

(VII) It is enough to wear ordinary medical masks on the way home and keep a distance of one meter from other people.

\section{For ICU staffs}

(I) If the ward lacks negative pressure, the patient should be quarantined in a single room with a large open window to ensure adequate air circulation. In order to prevent the spread of virus in the air, the central air conditioner should be turned off;

(II) Improving endotracheal intubation strategy is very important:

(i) It is the first choice to select fast-acting analgesic and sedative for suppression of cough, gag reflex in advance. Fast-acting neuromuscular blocker (Rocuronium bromide) to strengthen inhibiting respiration and avoid aerosols generating;

(ii) Sufficient preparation before performance to shorten process of intubation by visual laryngoscope. Personalized mask ventilation, dual-circuit and small tidal volume $(6 \mathrm{~mL} / \mathrm{kg})$ for pre-oxygenation to reduce gas leakage;

(iii) A closed tracheal suction system during mechanical ventilation and filters on the exhalation end of ventilator to reduce the risk for air contamination;

(iv) The intubation process is suggested to occur within 1-3 minutes;

(v) To prevent aerosol formation, stop sputum aspiration during intubation if the airway is unobstructed;

(vi) Doctors performing intubation can make their own headgear with disposable sterile disinfection towels if they do not have other PPE (Figure 1).

(III) After completing fibro-bronchoscope inspection, please pull out the mirror slowly, wipe the tube with gauze from top to bottom and plug the suction hole at the same time;

(IV) Cover the patient's nose and mouth during intubation to avoid splashing of secretions (Figure 1);

(V) Disposable sterile disinfection towel can be used as a mask, neck protector and headgear;

(VI) For intubated patients, non-invasive ventilator can be temporarily used instead but need to add an exhalation valve at the proximal end of the tube when the invasive ventilators are unavailable;

(VII) Contaminated PPEs must be detached in the buffer area. 


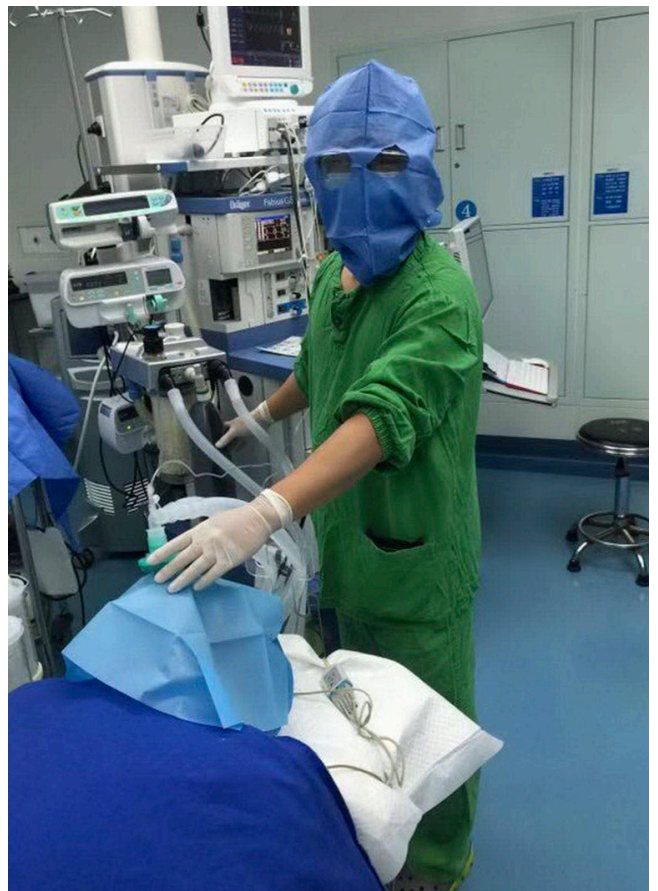

Figure 1 Making own headgear with disposable sterile disinfection towels before intubation

\section{The above recommendations apply only to alternative protection options in the absence of PPE}

Under the circumstances of severe shortage of PPE for medical staffs all over the world, we summarize our own experience for foreign medical colleagues on how to rescue serious patients and protect themselves in order to

Cite this article as: Luo H, Zhang S, Lin Y, Huang B, Tu Y, Li Y, Zhou C, Wang X. Experience and advice from single medical center: how to rescue patients with serious COVID-19 and protect medical staffs without sufficient personal protective equipment. Cardiovasc Diagn Ther 2020;10(3):639-641. doi: 10.21037/cdt-20-379 strengthen global communication of medical experts in the fight against the disease.

\section{Acknowledgements}

We would like to extend our appreciation to Dr. Mingling Wang for providing us the photo.

Funding: None.

\section{Footnote}

Conflicts of Interest: All authors have completed the ICMJE uniform disclosure form (http://dx.doi.org/10.21037/cdt20-379). HL serves as an unpaid editorial board member of Cardiovascular Diagnosis and Therapy from Jul 2019 to Jun 2021. The other authors have no other conflicts of interest to declare.

Ethical statement: The authors are accountable for all aspects of the work in ensuring that questions related to the accuracy or integrity of any part of the work are appropriately investigated and resolved.

Open Access Statement: This is an Open Access article distributed in accordance with the Creative Commons Attribution-NonCommercial-NoDerivs 4.0 International License (CC BY-NC-ND 4.0), which permits the noncommercial replication and distribution of the article with the strict proviso that no changes or edits are made and the original work is properly cited (including links to both the formal publication through the relevant DOI and the license). See: https://creativecommons.org/licenses/by-nc-nd/4.0/. 